\title{
Aspectos relacionados ao estabelecimento e à manutenção do aleitamento materno exclusivo na perspectiva de mulheres atendidas em uma unidade básica de saúde *
}

\author{
Elizabeth Fujimori ${ }^{1}$ \\ Eunice Nakamura ${ }^{2}$ \\ Marcela Melatti Gomes ${ }^{3}$ \\ Luciana Albuquerque de Jesus ${ }^{4}$ \\ Magda Andrade Rezende ${ }^{5}$
}

FUJIMORI, E. et al. Issues involved in establishing and maintaining exclusive breastfeeding, from the perspective of women attended at a primary healthcare unit.

Interface - Comunic., Saude, Educ., v.14, n.33, p.315-27, abr./jun. 2010.

This qualitative study aimed to investigate the issues involved in establishing and maintaining exclusive breastfeeding from the women's perspective. It was conducted with 12 mothers of infants less than six months of age who were attended at a primary healthcare unit. Semistructured interviews were recorded, transcribed and subjected to content analysis, which revealed the following categories: nipple trauma; free demand; "weak breast milk"; breastfeeding women's psychological health; previous breastfeeding experience; breastfeeding and women's multiple roles; and influence of close people.

Establishment of exclusive breastfeeding was associated with experiences and perceptions about breast milk sufficiency, thereby causing concern and insecurity. Close people, especially family members, influenced the establishment and maintenance of exclusive breastfeeding, as did women's work overload inside and outside home. Knowledge of issues that facilitate or hinder establishment and maintenance of breastfeeding is essential for guiding health professionals' actions.

Keywords: Breastfeeding. Interpersonal relations. Social support. Qualitative research.
Com a proposta de conhecer aspectos que envolvem o período de estabelecimento e manutenção do aleitamento materno exclusivo (AME), na perspectiva de mulheres, realizou-se estudo qualitativo com 12 mães de lactentes menores de seis meses, atendidas em unidade básica de saúde. Entrevistas semiestruturadas, gravadas, transcritas e submetidas à análise de conteúdo revelaram as categorias: traumas mamilares; livre demanda; "leite fraco"; saúde psicológica da nutriz; experiência anterior em amamentação; amamentação e os múltiplos papéis da mulher; influência de pessoas próximas. $\mathrm{O}$ estabelecimento do AME associou-se a experiências e percepções acerca da suficiência do leite, gerando preocupações e insegurança. Pessoas próximas, em especial familiares, influenciam no estabelecimento e manutenção do $\mathrm{AME}$, da mesma forma que a sobrecarga de trabalho da mulher, dentro e fora do lar. É fundamental que os profissionais de saúde conheçam esses aspectos que dificultam ou que facilitam o estabelecimento e a manutenção do aleitamento materno para orientarem ações.

Palavras-chave: Aleitamento materno. Relações interpessoais. Apoio social. Pesquisa qualitativa.
Texto inédito, elaborado com base em pesquisa realizada com auxílio do CNPq (bolsa de iniciação científica), resultado de Monografia de Conclusão de Curso. Pesquisa aprovada pelo Comitê de Ética em Pesquisa da Escola de Enfermagem da USP (Processo n. 515/2005/ CEP-EEUSP).

${ }^{1}$ Departamento de Enfermagem em Saúde Coletiva, Escola de Enfermagem,

Universidade de São Paulo (EE/USP). Av. Dr. Enéas de Carvalho Aguiar, n.419. São Paulo, SP, Brasil. 05.403-000. efujimor@usp.br

2 Departamento Saúde, Educação e Sociedade, Universidade Federal de

São Paulo, Campus Baixada Santista.

${ }^{3}$ Hospital Alemão Oswaldo Cruz.

${ }^{4}$ Programa de Agentes Comunitários de Saúde, Itapecerica da Serra. ${ }^{5}$ Departamento de Enfermagem MaternoInfantil e Psiquiátrica, EE/USP. 


\section{Introdução}

São notórios os benefícios do aleitamento materno (AM) para a saúde da criança e da mulher. Investigações científicas desenvolvidas nas últimas décadas muito contribuíram para tal conhecimento e embasam a atual política de aleitamento materno em nosso país (Toma, Rea, 2008).

No entanto, o aleitamento materno não pode ser reduzido a uma ação de saúde, uma vez que é uma prática social permeada "por representações, valores e, inclusive, ideologias e ocorre de modos diferentes, a depender do período histórico e do estrato social considerado" (Rezende, Sawaya, Padilha, 2002, p.154). É importante que se tenha isto em mente ao se vislumbrarem as metas de promoção do aleitamento materno que o Ministério da Saúde preconiza (Brasil, 2002). Segundo estas, espera-se que o lactente seja amamentado com exclusividade (isto é, sem uso de chás, sucos, água ou alimentos sólidos, exceto medicamentos) durante seus primeiros seis meses de vida. Paradoxalmente, a recente II Pesquisa de Prevalência de Aleitamento Materno, realizada nas capitais dos estados e no distrito federal, revelou que a mediana de aleitamento materno exclusivo é de apenas 54 dias (Brasil, 2009). Assim, vêse que ainda estamos longe da meta proposta pelo Ministério da Saúde.

Consequentemente, este ainda é um desafio aos profissionais de saúde, uma vez que a amamentação depende das condições de vida e trabalho, do momento vivido pela mulher, de suas experiências anteriores, da trajetória cultural e, também, da compreensão que a sociedade tem a respeito da amamentação. Ajudar a mulher a estabelecer e manter essa prática é, portanto, uma tarefa bastante complexa. Os profissionais de saúde poderão dialogar melhor com as mulheres, caso conheçam suas visões particulares sobre o assunto. Desta forma, este estudo foi delineado com o objetivo de se conhecerem os aspectos que envolvem o período de estabelecimento e manutenção do aleitamento materno exclusivo (AME), na perspectiva de um grupo de mulheres atendidas em uma unidade básica de saúde. Espera-se contribuir para o conhecimento de aspectos que atuam no estabelecimento e manutenção do $\mathrm{AME}$, bem como identificar as principais razões que conduzem à interrupção precoce dessa prática.

\section{Percurso metodológico}

Trata-se de um estudo qualitativo que buscou apreender aspectos subjetivos relacionados ao período de estabelecimento e manutenção do $A M E$, segundo um grupo particular de mulheres, mães de lactentes com até seis meses de idade. Ao ressaltar a perspectiva de um grupo de mulheres em relação ao estabelecimento e manutenção do $A M E$, a pesquisa procurou evidenciar os diferentes sentidos que $o$ aleitamento adquire para elas. É nisso que consiste o trabalho do pesquisador em estudos qualitativos: interpretar atos, fatos e falas, tornando compreensíveis as experiências vividas por diferentes grupos sociais (Martin et al., 2006). O projeto foi aprovado por Comitê de Ética em Pesquisa, e todos os aspectos éticos constantes na Resolução 196/96 do Conselho Nacional de Saúde foram contemplados.

O estudo foi desenvolvido com 12 mulheres que levavam seus filhos para consulta de puericultura a uma unidade básica de saúde do município de Itapecerica da Serra, região metropolitana de São Paulo, SP. Foram incluídas somente mães de crianças que haviam nascido a termo e com peso adequado para a idade gestacional. A obtenção de entrevistas foi interrompida quando se obteve redundância dos temas, ou seja, quando se atingiu o ponto de saturação, com repetições de informações (Minayo, 1999).

As mulheres foram entrevistadas individualmente na própria unidade de saúde, em local que resguardava sua privacidade, por uma enfermeira ou aluna de graduação em enfermagem, em julho e agosto de 2006. Usou-se um roteiro, previamente elaborado pelas pesquisadoras, que compreendia dados de identificação, bem como questões desencadeadoras relacionadas à alimentação do bebê. Estas contemplavam conhecimentos e práticas das mulheres acerca da alimentação do lactente, preocupações e dificuldades referentes ao estabelecimento e manutenção do AME. Buscou-se saber também quem as ajudava a tomar as decisões sobre a alimentação do bebê. As entrevistas foram gravadas e posteriormente transcritas. 
A idade das mulheres variou de 17 a 37 anos, sendo três com menos de vinte anos, sete com idade de vinte a 26 anos, e duas com mais de 35. Metade era primigesta e a outra metade multípara que já tinha vivenciado de duas a nove gestações. Nove tinham união estável, quer sob o ponto de vista legal, quer não. Em relação à escolaridade, três tinham Ensino Médio completo; cinco o Ensino Fundamental completo, e quatro o Ensino Fundamental incompleto. Quatro exerciam atividade remunerada fora do lar e nove tinham renda familiar inferior a dois salários-mínimos.

A idade dos lactentes variava de sete dias a cinco meses e 27 dias. Sete tinham menos de 35 dias, sendo três com menos de 15 dias. Nove encontravam-se em aleitamento materno e desses, cinco estavam em AME.

Para analisar as entrevistas, empregou-se o método de análise temática de conteúdo, que consiste em descobrir os núcleos de sentido relacionados ao objetivo da pesquisa e formular as ligações entre eles (Bardin, 1977). Os passos para a análise envolveram: leitura exaustiva dos textos transcritos, identificação dos temas, sua organização em núcleos temáticos e organização das relações entre estes. Tal caminho possibilitou identificar como temas relevantes das entrevistas: os traumas mamilares; a livre demanda; o "leite fraco"; a saúde psicológica da nutriz; experiência anterior em amamentação; amamentação e os múltiplos papéis da mulher; e a influência de pessoas próximas. A discussão foi fundamentada na concepção de aleitamento materno enquanto prática social (Almeida, Novak, 2004; Rezende, Sawaya, Padilha, 2002), que demanda um cuidado centrado em valores humanísticos, isto é, uma abordagem de compreensão e de apoio (Rezende, 2000), ao invés da prescritiva tradicional.

\section{Resultados e discussão}

Apresentam-se, a seguir, as categorias temáticas que emergiram da análise das entrevistas, referentes ao estabelecimento e à manutenção do AME.

\section{Do estabelecimento da amamentação}

Ao serem estimuladas a falar sobre o tipo de alimento mais apropriado para o bebê, as mães demonstraram saber que era o leite materno exclusivo até os seis meses. Entretanto, dentre os cinco lactentes que permaneciam em $A M E$, a característica comum era a pouca idade, pois o mais velho tinha 35 dias. No caso das outras sete mulheres, três estavam com os bebês desmamados completamente e quatro parcialmente. O AME dessas crianças tinha durado um mês, no máximo.

Tal como no caso destas mulheres, estudo desenvolvido com puérperas revelou que, dentre as informações obtidas no pré-natal, a duração do AME até o sexto mês foi considerada a mais importante e a de maior fixação, indicando provável ênfase nessa questão (Sandre-Pereira et al., 2000). Apesar disso, os dados da II Pesquisa de Prevalência de Aleitamento Materno mostraram que a proporção de lactentes com menos de quatro meses em AME continua baixa, apenas 52\% em 2008 (Brasil, 2009). Assim, ainda que tenham conseguido estabelecer a prática do AME e tenham conhecimento de sua importância, não conseguem mantê-lo pelo período recomendado. Vê-se, portanto, que o amamentar passa por outras questões, além do conhecimento sobre a importância dessa prática.

Os fatores que podem influenciar essa questão são explorados a seguir.

\section{Os traumas mamilares}

Problemas com mamilos doloridos, fissuras e ingurgitamento mamário são dificuldades que interferem no estabelecimento e sucesso da amamentação (Araújo et al., 2008; Carvalhaes, Parada, Costa, 2007; Osório, Queiroz, 2007; Parada et al., 2005; Ramos, Almeida, 2003). A técnica da amamentação é importante para prevenir dor e traumas mamilares, e a adoção de medidas profiláticas durante o ciclo gravídico-puerperal tende a evitar tais problemas comuns, que além de interferirem na dinâmica de sucção e extração do leite, certamente dificultam o estabelecimento do aleitamento materno (Sanches, 2004). 
Várias mães referiram ter tido algum problema relacionado à mama, fazendo uso de expressões como "machucou, empedrou, rachou, doeu" para descrever o que dificultou o estabelecimento da amamentação, causando-Ihes vontade de desistir dessa prática:

\begin{abstract}
"Nossa, eu tinha bastante dificuldade de dar de mamar pra ela no peito, ainda mais porque eu estava com muita dor, Nossa Senhora. Eu tava com tanta dor que deu vontade de desistir". (mulher de 35 anos, um filho, lactente de sete dias)

“[bico]... rachou .... muito [...] Aí eu passava óleo de amêndoas, assim um pouquinho em volta né, pra não machucar né, porque machucou muito mesmo". (mulher de 25 anos, um
\end{abstract} filho, lactente de cinco meses e 27 dias)

"Rachou, feriu". (mulher de 25 anos, dois filhos, lactente de dois meses e 23 dias)

Apesar da dor e de outros problemas causados pelos ferimentos na mama, houve uma nutriz que não desistiu, como confirma seu depoimento:

\footnotetext{
“Eu tive complicação, né, porque machucou e tudo, mas eu não desisti [...] dela sugar eu machuquei, saiu sangue, porque tava só o colostro. Não vinha, aí saiu muito sangue. Aí eu deixei de dar um até sarar e dei só o outro que não tava tão machucado [...] Assim que chegou o leite ficou todo empedrado, doía, fez íngua debaixo do braço". (mulher de 25 anos, um filho, lactente de um mês e cinco dias)
}

Intercorrências dessa natureza evidenciam a necessidade de uma rede de apoio à nutriz, sobretudo nas primeiras semanas após o parto (Carvalhaes, Parada, Costa, 2007; Ramos, Almeida, 2003).

Considerado um momento delicado, o período puerperal requer atenção e cuidados especiais da equipe de saúde, que deve proceder a uma avaliação criteriosa da amamentação (Sanches, 2004). Assim, para que a prática do AM seja efetivamente estabelecida, além da vontade da mulher, é fundamental que ela esteja inserida em um ambiente favorável e que conte com apoio.

Ademais, merecem destaque, no discurso de mulheres, os relatos de insensibilidade dos profissionais de saúde frente à dor, que implica não acolher e ajudar a mulher e contribui para o abandono da amamentação (Ramos, Almeida, 2003). Além da falta de sensibilidade em acolher a mulher no processo de decisão e adaptação ao AM, é importante lembrar que a assistência parte de um pressuposto de que a amamentação é algo natural, além de um dever. Por consequência, a mulher é reduzida à sua função nutridora, negando-se sua condição de ser humano envolvido no processo (Rezende, Sawaya, Padilha, 2002; Rezende, 2000). Aliás, processo delicado, longo e trabalhoso, pois vai além do fornecimento de alimento. Trata-se da construção de uma nova identidade, enquanto mãe, ou construção da identidade de mãe de um ser humano recém introduzido na dinâmica do grupo familiar.

\title{
A livre demanda
}

As mulheres entrevistadas referiram-se a intervalos bastante diferenciados em relação ao esquema de horários para o oferecimento do leite materno, independentemente da idade do bebê:

"[...] até agora eu não marquei, mas acho que é de uma, uma e meia, ela ta mamando". (mulher de 26 anos, dois filhos, lactente de 22 dias)

"De duas em duas horas". (mulher de 35 anos, um filho, lactente de sete dias)

"[...] às vezes ela passa um pouquinho das três horas". (mulher de vinte anos, um filho, mãe de lactente de nove dias) 
“[...] não chega dá nem meia hora ela quer de novo, então fica praticamente quase de meia em meia hora o dia inteiro... à noite ela dorme mamando [...] ela fica a noite inteira assim dormindo e mamando". (mulher de 18 anos, dois filhos, lactente de 11 dias)

Eu deixo de uma hora a duas, mas se ela não pedir, no máximo duas horas, mas às vezes ela pede com quarenta, meia hora, ela tá pedindo aí eu dou [...]". (mulher de 25 anos, um filho, lactente de um mês e cinco dias)

"[...] uma hora, uma hora e meia antes e já quer". (mulher de 22 anos, dois filhos, mãe de lactente de um mês e cinco dias)

A livre demanda deve ser encorajada, pois a prática de amamentar sem restrições de horário associase a ganho de peso adequado, melhor estabelecimento e maior duração do aleitamento materno (Giugliani, 2000; Euclydes, 1997). Entretanto, mamadas com intervalos tão curtos, a cada trinta-quarenta minutos, ou mesmo de hora em hora, como referido por algumas mulheres, são preocupantes e podem indicar que o lactente não está pegando a mama corretamente. No entanto, não deve ser esquecido que a fome é mais frequente no AME devido à própria composição do leite materno, que é rapidamente digerido (Unicef, 2009).

A má pega pode ser causada por uma posição inadequada e torna a mamada ineficiente, " [...] com o bebê 'brigando' com a mama, ou mesmo recusando o peito, [...] vindo a reforçar a idéia errônea da mãe e de familiares de que o leite é insuficiente ou fraco" (Sanches, 2004, p.s157). A má pega prejudica o esvaziamento da mama e impede que a criança receba o leite do final da mamada, mais rico em gordura. Por consequência, pode haver diminuição da saciedade e a criança encurta o intervalo entre as mamadas. Os intervalos curtos tendem a aumentar a fermentação da lactose que pode agravar as cólicas, além de levar as mães a acharem que seu leite é fraco ou insuficiente, razão que também dificulta a manutenção do AME (Brasil, 2002).

Esta dificuldade pode chegar a constituir uma autêntica crise no processo de estabelecimento da amamentação, que poderia ser diminuída ou evitada, se os serviços de saúde estivessem organizados de modo a intervir de modo rápido e apoiador.

\section{O "leite fraco"}

A fala de várias mulheres mostrou preocupação em relação à suficiência de seu leite:

"[...] pensei que meu leite era muito fraco e não estava sustentando ela". (mulher de 23 anos, quatro filhos, mãe de lactente de quatro meses e um dia)

"[...] às vezes eu acho normal, às vezes eu acho já bem mais fraquinho [leite] do que os primeiros leites que saiu, na maternidade". (mulher de 26 anos, dois filhos, mãe de lactente de 22 dias)

"Eu acho que é muito fraco assim [...] porque às vezes o certo dela mamar é de três em três horas né, às vezes ela acorda bem antes...". (mulher de 22 anos, dois filhos, mãe de lactente de um mês e cinco dias)

"[...] mamava, mamava e continuava chorando, ai eu achava que não sustentava". (mulher de 35 anos, um filho, lactente de sete dias)

Logicamente, a mãe busca a causa e o modo de solucionar o mal-estar do bebê. Assim, o choro é interpretado como fome, e daí conjeturar que o "leite é fraco", e introduzir novos alimentos é um passo (Carvalhaes, Parada, Costa, 2007; Osório, Queiroz, 2007; Parada et al., 2005; Ramos, Almeida, 2003). 
Dessa forma, não causa admiração o achado de estudo que avaliou a opinião de mulheres sobre a quantidade de leite materno e constatou que, embora $83 \%$ das mulheres considerassem produzir leite suficiente, terminaram por introduzir leite artificial antes do quarto mês. As que referiram produzir quantidade insuficiente introduziram-no ainda mais precocemente (Borges, Philippi, 2003).

Para Ramos e Almeida (2003), a alegação de que o 'leite é fraco' sinaliza um pedido de ajuda das mulheres frente às dificuldades que estão vivendo. A resposta a este pedido não pode ser a que recebeu a mãe que traz o depoimento abaixo:

"[...] às vezes eu penso que o meu leite está secando [...] eu fiquei gripada, aí eu fiquei falando 'tá fraco', mas lá no banco de leite falaram que não existe esse negócio de leite fraco, que é lenda". (mulher de 25 anos, um filho, mãe de lactente de um mês e cinco dias)

Dizer que 'leite fraco é lenda' demonstra que a equipe não conseguiu ouvir o pedido nas entrelinhas, pedido, aliás, que nem a própria nutriz conseguiu formular de modo claro. Já pudemos observar em nossa prática que, na maior parte das vezes, a mulher nem tem consciência da dinamicidade e ambivalência que está vivendo no momento.

\section{Saúde psicológica da nutriz}

A depressão, que chega a acometer mais de um terço das mulheres no período puerperal (Vitolo et al., 2007; Cruz, Simões, Faisal-Cury, 2005), determina frequências significativamente menores de AME, como revelou o estudo de Vitolo et al. (2007).

No presente estudo, uma das mulheres relatou depressão, que dificultou o estabelecimento e manutenção da amamentação:

“[...] comecei a dar peito, aí o que acontece que eu tive um começo de depressão, e tomo uns remédios fortes, aí ela só toma mamadeira agora [...].Eu tomo fluorexitina, eu tomo dois calmantes por dia e um à noite de Diazepan ${ }^{\circledR}$ [...] Aí o médico falou que tava atrapalhando, né [...] Aí eu parei porque, ela falou para mim que ela tava dormindo muito, a neném... Tava passando muito pro leite... Aí é só mamadeira agora. [...], o pediatra também falou pra mim, no começo, que não era para parar o peito, que não tinha nada a ver, mas aí eu vi, fui percebendo nela ... que tava passando muito pelo leite, porque ela tava o tempo todo dormindo. Ela tremia enquanto dormia, tipo eu tremo a noite assim ... ela ficava do mesmo jeito, aí eu falei então vou parar, né? Aí eu fui e parei de dar o peito pra ela". (mulher de 23 anos, quatro filhos, mãe de lactente de quatro meses e um dia)

Nesses casos a rede de apoio é fundamental. Dessen e Braz (2000) chamam atenção para a importância da rede social na manutenção da saúde mental e enfrentamento de situações potencialmente estressantes como são as fases de transição decorrentes do nascimento de filhos. São várias as pessoas que podem oferecer suporte, destacando-se, entre elas, membros da própria família, vizinhos e profissionais. O apoio pode ser: material, financeiro, execução de tarefas domésticas, cuidado das outras crianças, orientação e, por último, mas não menos importante, emocional.

Tal suporte é fundamental na fase de estabelecimento e manutenção do aleitamento. No entanto, implica, por parte dos serviços de saúde, a reorganização em torno de outra lógica. Família e comunidade são, ao mesmo tempo, sujeito e suporte do cuidado. Esse, por sua vez, passa a abarcar a prevenção do isolamento social como estratégia de promoção do AM.

\section{Experiência anterior de amamentação}

A falta de experiência também se configura como uma condição que dificulta o estabelecimento da amamentação:

"[...] o primeiro mês pra mim foi muito complicado, primeiro filho, muito nova, sem experiência, acho que foi muito difícil... não sabia dar de mamar, tinha medo, achava que ele 
não queria meu peito, achava que não tinha leite [...]". (mulher de 19 anos, um filho, lactente de três meses e 14 dias)

Esse depoimento reitera a literatura, segundo a qual a insegurança materna decorrente da falta de experiência, tanto pessoal, quanto por observação de outras mulheres amamentando, é fator que influencia a decisão por essa prática e sua manutenção. É importante salientar, no entanto, que embora possa ser uma influência positiva ter visto outras amamentarem, ou ter amamentado outro filho com sucesso, há que se considerar que os atos humanos não se constituem em mera repetição. A amamentação é um processo diferente a cada experiência, e por isso precisa ser "aprendido" e "reaprendido" (Ramos, Almeida, 2003; Rezende et al., 2002).

Tais fatos reforçam a necessidade de apoio, seja de familiar, amigo, ou profissional de saúde que ajude a mãe a construir competências para cuidar do bebê. Competências essas intimamente relacionadas à própria autoimagem, especialmente se for uma 'mãe de primeira viagem' (Unicef, 2009).

Apoio é tão importante que integra os dez passos da Iniciativa Hospital Amigo da Criança. Para contemplá-lo recomenda-se o encaminhamento da mãe, após a alta da maternidade, a grupos de apoio ao aleitamento materno (Unicef, 2009). O mesmo é recomendado pela Iniciativa Unidade Básica Amiga da Amamentação (IUBAAM), que prevê a implementação de grupos de apoio à amamentação, acessíveis a todas as gestantes e mães, com envolvimento dos familiares (Oliveira, Camacho, Souza, 2005).

Apesar das recomendações, sabe-se que os grupos de apoio não estão presentes de forma generalizada em nosso meio. Esse é, pois, um dos desafios a serem enfrentados para apoiar o estabelecimento da amamentação e efetivamente contribuir para prolongar a duração do AME.

\section{Da manutenção do aleitamento materno no dia a dia}

Constata-se que o estabelecimento da amamentação não é uma tarefa fácil, natural ou intuitiva (Rotemberg, Vargas, 2004; Nakano, Mamede, 1999; Silva 1999). Trata-se de uma experiência complexa que envolve uma rede de fatores biológicos, psicológicos e sociais e, também, é mediada pela própria experiência da mulher (Rezende et al., 2002). Assim, a manutenção da amamentação pelas mulheres deste estudo também se configurou como experiência complexa e de enfrentamento.

\section{Amamentação e os múltiplos papéis da mulher}

Relatada como difícil e desgastante, a prática da amamentação envolve: preocupação, insegurança, ansiedade, angústia, cansaço e sobrecarga adicional à jornada de trabalho da mulher, tanto na esfera pública quanto privada (Osório, Queiróz, 2007; Silva, Moura, Silva, 2007).

Além disso, trata-se de uma vivência permeada por conflitos e contradições, uma vez que amamentar prazerosamente o filho é o perfil que o meio social espera de uma boa mãe (Takushi et al., 2008; Rezende, Sawaya, Padilha, 2002; Nakano, Mamede, 1999; Silva 1999). Os depoimentos a seguir revelam sentimentos vivenciados pelas mulheres, porém difíceis de serem explicitados pela nutriz, por não estarem de acordo com a 'representação idealizada da mãe amamentadora':

\footnotetext{
“Mas é eu não sinto muita vontade de dar de mamar não [...] porque eu nunca gostei de dar mamar no peito. Ah, eu acho que me incomoda, me irrita, não sei se é por causa da depressão, o que é, mas me irrita bastante...". (mulher de 23 anos, quatro filhos, mãe de lactente de quatro meses e um dia)

"É porque às vezes eu não tinha muita paciência de ficar dando [peito]. [...] só quem passa é que sabe". (mulher de 22 anos, dois filhos, mãe de lactente de um mês e cinco dias)
}

Como referido, trata-se de posições difíceis de serem assumidas numa sociedade em que amamentar o filho é esperado. Explicitar que não quer amamentar, não gosta ou não tem paciência não condiz com o perfil idealizado de mãe (Silva, Moura, Silva, 2007; Nakano, Mamede, 1999). Como a 
amamentação limita e interfere significativamente na vida da mulher, sentimentos de impaciência, irritação e raiva podem se manifestar (Osório, Queiroz, 2007; Ramos, Almeida, 2003). Assim, há que se considerar a possibilidade de que a amamentação nem sempre se concretize como uma experiência positiva, sendo muitas vezes um fardo, pela obrigação, pela expectativa da sociedade e pelos múltiplos papéis que a mulher desempenha como mãe e mulher. Nesse contexto, situações conflitantes, com a coexistência de sentimentos ambivalentes e contraditórios, têm sido constatadas (Silva, Moura, Silva, 2007; Sandre-Pereira et al., 2000).

Além de amamentar e cuidar do lactente e de outros filhos, há os afazeres domésticos e, em muitas situações, o trabalho fora do lar. Algumas mulheres relataram oferecer outro leite ou outros alimentos associados ao leite materno, independente da idade de seus bebês, tanto pela necessidade de trabalhar, como pela sobrecarga do trabalho doméstico e com outros filhos:

\begin{abstract}
“Ele mama no peito e toma leite na mamadeira, leite ninho. O certo era só o peito, mas a necessidade [de trabalhar] obriga a gente a dar outras coisas [...] Eu não posso ficar dentro de casa. Tenho muito menino, meu marido tá parado. [...] difícil, bem difícil, tem hora que entra em pânico. Uma que a criança nessa idade não deixa dormir direito de noite. Aí de manhã ainda tem que enfrentar uma mulher de 86 anos, que é muito brava, a gente fica ... tem hora que dá desespero ... mas precisa trabalhar, alguém tem que suprir a casa". (mulher de 37 anos, nove filhos, mãe de lactente de 16 dias)

“Pra mim, eu acho que só o peito né, mas só quem passa é que sabe que não é sempre assim que se tá, ainda mais que eu tenho outro filho, tenho a casa, aí é mais difícil, mas eu procuro dar mais o peito do que outro leite [...]". (mulher de 22 anos, dois filhos, mãe de lactente de um mês e cinco dias)
\end{abstract}

A necessidade de trabalhar tem sido condicionante de sobrevivência para a mulher contemporânea. Dados da Pesquisa Nacional de Demografia e Saúde (Cunha, 2008) indicam que 54\% das mulheres em idade reprodutiva encontram-se inseridas no mercado de trabalho. No entanto, a maior parte (65\%) não tem vínculo legal, isto é, não tem direitos trabalhistas, como licença-maternidade, férias remuneradas, décimo-terceiro salário, entre outros. As mulheres de menor escolaridade são as mais fortemente atingidas por essa situação, pois a relação licença maternidade e maior duração do AME é estabelecida (Vianna et al., 2007). Entretanto, mesmo mães empregadas ao abrigo da lei enfrentam dificuldades para fazer valerem os direitos trabalhistas, como mostra pesquisa realizada na Paraíba: apenas $52 \%$ das mulheres legalmente empregadas gozaram licença maternidade, configurando dificuldade que também deve ser levada em conta. $O$ trabalho também foi um motivo referido para não pretender amamentar, pois a criança poderia sofrer com o desmame brusco no retorno ao trabalho (Takushi et al., 2008).

\title{
Influência de pessoas próximas
}

Mãe, sogra (avós da criança), irmãs, cunhadas, companheiro, vizinhos ou pessoas com mais experiência influenciam a prática da amamentação e, na tentativa de ajudar a resolver dúvidas e inseguranças, podem contribuir para a interrupção do $A M E$, como revelam as falas:

“[...] ele tava com muita cólica. Eu passei na farmácia e um colega meu disse: 'dá um tal de Luftal que é bom' ou um 'berderrutine', alguma coisa assim, ah é bom. Aí eu dei o tal do luftal, mas, foi só com um mês. Agora eu não dei mais. Agora eu tô tentando mais o chazinho, ou o dormir encostado em mim que é o que eu mais faço, dormir com ele na minha barriga". (mulher de 19 anos, um filho, lactente de três meses e 14 dias)

“É, porque ela queria mamar a noite inteira, né? Falaram [mãe, sogra] para comprar o chá, porque como tá na época de frio, aí, com o chá ela vai dormir mais tempo. Vai ficar mais calma". (mulher de 22 anos, dois filhos, mãe de lactente de um mês e cinco dias) 


\begin{abstract}
"Falaram [os vizinhos] que, se de repente o leite não sustentar, o do peito, que pode dar outro leite, né?" (mulher de 35 anos, um filho, lactente de sete dias)

“Eu sempre acreditei que só o peito é suficiente, mas as pessoas começam a falar: 'você tem que dar sopinha' ...". (mulher de 25 anos, um filho, lactente de um mês e cinco dias)

“[...] meu esposo, ele acha que não tá, que o menino não tá sustentando no peito. Ele queria que eu desse mamadeira". (mulher de 19 anos, um filho, lactente de três meses e 14 dias)
\end{abstract}

Constata-se, pois, a influência do meio relacional próximo na introdução precoce de outros alimentos, o que em contextos urbanos sabidamente conduz à interrupção da amamentação. Frente a tantas interferências externas, a mulher toma decisões com base nas interações que mantém com o meio social (Ramos, Almeida, 2003), porém é no âmbito familiar que as nutrizes buscam ajuda e acolhimento, que tradicionalmente provêm do próprio gênero, ou seja, mães, sogras, irmãs, cunhadas e amigas (Nakano et al., 2007):

"Olha como eu tenho uma irmã mais velha que tem filhos, eu pergunto pra ela". (mulher de 26 anos, dois filhos, lactente de 22 dias)

“Às vezes eu pergunto pra minha cunhada [...] Porque é o meu primeiro, né? [...] ela já tem mais experiência". (mulher de 35 anos, um filho, lactente de sete dias)

"Procuro meu marido, pergunto para ele, pois como ele já teve uma filha, né? Eu pergunto para ele se é certo". (mulher de 19 anos, um filho, lactente de três meses e 14 dias)

Assim, para resistir às interferências de familiares e pessoas próximas, há valorização da orientação profissional - do pediatra, no caso da fala abaixo -, o que indica um aspecto positivo:

“[...] ele [marido] falou pra mim ajudar na mamadeira, no leite de caixinha, mas eu não dei ainda porque eu quero conversar com a pediatra para ver o que eu posso fazer. Eu tenho medo de dar e fazer mal. [...] minha mãe, que por ela ter tido filho, falou que chá é bom". (mulher de 19 anos, um filho, lactente de três meses e 14 dias)

“Eu sempre acreditei que só o peito é suficiente, mas as pessoas começam a falar: 'você tem que dar sopinha' [...] ela não teve consulta com a pediatra, para ter uma orientação de gente formada, né, porque a gente ouve cada coisa na rua, só que eu não quero cair [...]". (mulher de 25 anos, um filho, lactente de um mês e cinco dias)

Mães assistidas pelo Programa de Saúde da Família recorriam, sobretudo, aos médicos e, a seguir, às enfermeiras (Parada et al., 2005), de forma que cabe indagar se o familiar ocupa tal espaço porque o profissional de saúde não está acessível nos momentos em que a nutriz tem maior necessidade de informação e de apoio.

De acordo com as entrevistadas, percebe-se que as informações dos profissionais referem-se à manutenção do AME (tempo de duração) e se limitam a aspectos normativos gerais:

\footnotetext{
"Todas as enfermeiras dizem amamente até os seis meses, se você não conseguir dar o peito vai tentando, se ele não pegar um pega o outro e assim vai". (mulher de 18 anos, dois filhos, lactente de 11 dias)
}

"A informação é a respeito de dar o peito, não dar chupeta, nem mamadeira". (mulher de 23 anos, quatro filhos, lactente de quatro meses e um dia) 
“Foi uma enfermeira [...] explicou a importância do leite do peito pro bebê, como amamentar". (mulher de vinte anos, um filho, lactente de nove dias)

Somente uma entrevistada disse que o médico fornecia informações mais detalhadas, embora ainda normativas:

"[...] nas consultas, o doutor explicava como amamentar, como cuidar do peito, lavar, sempre lavadinho né, no banho". (mulher de 26 anos, dois filhos, lactente de 22 dias)

Os profissionais de saúde orientam para que o AME seja mantido nos seis primeiros meses de vida, porém apenas informar não é suficiente, pois as situações cotidianas são específicas para cada mulher e dependem de sua história e vivência, havendo necessidade de atendimento rápido por ocasião das crises, que são mais comuns nos primeiros dias e semanas após o parto.

\section{Conclusões}

O estabelecimento do aleitamento materno associa-se às experiências vivenciadas pelas mulheres, suas percepções acerca do leite materno e sobre si próprias enquanto nutrizes, além das inseguranças e dificuldades enfrentadas. As pessoas mais experientes, em especial familiares, exercem influência importante nas condutas relacionadas à amamentação.

Os serviços de saúde parecem exercer influência, porém as situações relatadas pelas mulheres sugerem a importância de os profissionais de saúde estarem disponíveis para ajudá-las no dia a dia. Os depoimentos indicaram que não basta a mulher querer amamentar, conhecer suas vantagens e duração recomendada, pois para que essa prática seja efetivamente estabelecida e mantida, ela precisa de apoio e de ser compreendida na particularidade de sua realidade sociocultural.

As abordagens precisam deixar de valorizar apenas vantagens bioquímicas e fisiológicas do leite materno para a saúde da criança e incorporar o entendimento do significado da maternidade e da corporeidade no cotidiano da mulher contemporânea, exaurida pelo mundo regrado. Há que se encontrarem estratégias que reconheçam o lugar da mulher e as valorizem como sujeito de direito e dona do seu corpo, evitando-se reproduzir o discurso da culpabilização e da responsabilização, identificado em vários estudos.

Além da vontade materna e da habilidade dos profissionais de saúde em promover o aleitamento materno da forma acima destacada, é preciso considerar que o sucesso da prática da amamentação depende também de políticas governamentais adequadas e do apoio e participação de toda a sociedade.

\section{Colaboradores}

Elizabeth Fujimori participou da concepção da pesquisa, orientou todas as etapas de realização e avaliação do trabalho e foi responsável pela redação e revisão do artigo. Eunice Nakamura colaborou na análise dos dados empíricos e na redação final do manuscrito. Marcela Mellatti Gomes e Luciana Albuquerque de Jesus contribuíram no planejamento da pesquisa, coleta e análise dos dados. Magda Andrade Rezende colaborou na redação final do manuscrito. 


\section{Referências}

ALMEIDA, J.A.G.; NOVAK, F.R. Amamentação: um híbrido natureza-cultura. J. Pediatr., v.80, n.5, p.S119-25, 2004.

ARAÚJO, O.D. et al. Aleitamento materno: fatores que levam ao desmame precoce. Rev. Bras. Enferm., v.61, n.4, p.488-92, 2008.

BARDIN, L. Análise de conteúdo. Lisboa: Edições 70, 1977.

BORGES, A.L.V.; PHILIPPI, S.T. Opinião de mulheres de uma unidade de saúde da família sobre a quantidade de leite materno produzido. Rev. Latino-am. Enferm., v.11, n.3, p.287-92, 2003.

BRASIL. Ministério da Saúde. II Pesquisa de prevalência de aleitamento materno nas capitais brasileiras e Distrito Federal. Brasília: Ministério da Saúde, 2009. Disponível em: <http://portal.saude.gov.br/portal/arquivos/pdf/pesquisa_pdf.pdf>. Acesso em: 9 set. 2009.

Ministério da Saúde. Organização Panamericana da Saúde. Guia alimentar para crianças menores de dois anos. Brasília: Ministério da Saúde, 2002. (Série A. Normas e Manuais Técnicos n.107). Disponível em: <http://www.fef.br/biblioteca/arquivos/ data/guia_criancas.pdf $>$. Acesso em: 1 set. 2009.

CARVALHAES, M.A.B.L.; PARADA, C.M.G.L.; COSTA, M.P. Fatores associados à situação do aleitamento materno exclusivo em crianças menores de quatro meses, em BotucatuSP. Rev. Latino-am. Enferm., v.15, n.1, p.62-9, 2007.

CRUZ, E.B.S.; SIMÕES, G.L.; FAISAL-CURY, A. Rastreamento da depressão pós-parto em mulheres atendidas pelo Programa de Saúde da Família. Rev. Bras. Ginecol. Obstet., v.27, n.4, p.181-8, 2005.

CUNHA, E.M.G.P. Características sociodemográficas das mulheres entrevistadas. In: BRASIL. Ministério da Saúde. PNDS 2006 - Pesquisa nacional de demografia e saúde da criança e da mulher. Brasília: Ministério da Saúde, 2008. p.86-112. Disponível em: <http://bvsms.saude.gov.br/bvs/pnds/index.php>. Acesso em: 24 ago. 2009.

DESSEN, M.A.; BRAZ, M.P. Rede social de apoio durante transições familiares decorrentes do nascimento de filhos. Psic. Teor. Pesq., v.16, n.3, p.1-18, 2000.

EUCLYDES, M.P. Nutrição do lactente: base científica para uma alimentação adequada. Viçosa: UFV, 1997.

GIUGLIANI, E.R.J. O aleitamento materno na prática clínica. J. Pediatr., v.76, n.3, p.S238-52, 2000.

MARTIN, D. et al. Noções de significado nas pesquisas qualitativas em saúde: a contribuição da antropologia. Rev. Saude Publica, v.40, n.1, p.178-80, 2006.

MINAYO, M.C.S. O desafio do conhecimento: pesquisa qualitativa em saúde. Rio de Janeiro: Hucitec/Abrasco, 1999.

NAKANO, A.M.S.; MAMEDE, M.V. A prática do aleitamento materno em um grupo de mulheres brasileiras: movimento de acomodação e resistência. Rev. Latino-am.

Enferm., v.7, n.3, p.69-76, 1999.

NAKANO, M.A.S. et al. O espaço social das mulheres e a referência para o cuidado na prática da amamentação. Rev. Latino-am. Enferm., v.15, n.2, p.230-8, 2007.

OLIVEIRA, M.I.C.; CAMACHO, L.A.B.; SOUZA, I.E.O. Promoção, proteção e apoio à amamentação na atenção primária à saúde no Estado do Rio de Janeiro, Brasil: uma política de saúde pública baseada em evidência. Cad. Saude Publica, v.21, n.6, p.1901-10, 2005. 
OSÓRIO, C.M.; QUEIROZ, A.B.Z. Representações sociais de mulheres sobre a amamentação: teste de associação livre de idéias acerca da interrupção precoce do aleitamento materno exclusivo. Esc. Anna Nery Rev. Enferm., v.11, n.2, p.261-7, 2007.

PARADA, C.M.G.L. et al. Situação do aleitamento materno em população assistida pelo programa de saúde da família-PSF. Rev. Latino-am. Enferm., v.13, n.3, 407-14, 2005.

RAMOS, C.V.; ALMEIDA, J.A.G. Alegações maternas para o desmame: estudo qualitativo. J. Pediatr., v.79, n.5, p.385-90, 2003.

REZENDE, M.A. Amamentação: uma necessária mudança de enfoque. Rev. Bras. Enferm., v.34, n.2, p.226-9, 2000.

REZENDE, M.A. et al. O processo de comunicação na promoção do aleitamento materno. Rev. Latino-am. Enferm., v.10, n.2, p.234-8, 2002.

REZENDE, M.A.; SAWAIA, B.B.; PADILHA, K.G. Mãe boa amamenta ou a força da ideologia. Fam. Saude Desenv., v.4, n.2, p.154-62, 2002.

ROTENBERG, S.; DE VARGAS, S. Práticas alimentares e o cuidado da saúde: da alimentação da criança à alimentação da família. Rev. Bras. Saude Mater. Infant., v.4, n.1, p.85-94, 2004.

SANCHES, M.T.C. Manejo clínico das disfunções orais na amamentação. J. Pediatr., v.80, n.5, p.s155-62, 2004

SANDRE-PEREIRA, G. et. al. Conhecimentos maternos sobre amamentação entre puérperas inscritas em programa de pré-natal. Cad. Saude Publica, v.16, n.2, p.457-66, 2000.

SILVA, I.A. Construindo perspectivas sobre a assistência em amamentação: um processo interacional. 1999. Tese (Livre-docência) - Escola de Enfermagem, Universidade de São Paulo, São Paulo. 1999.

SILVA, M.B.C.; MOURA, M.E.B.; SILVA, A.O. Desmame precoce: representações sociais de mães. Rev. Eletr. Enferm., v.9, n.1, p.31-50, 2007. Disponível em: <http:// www.fen.ufg.br/revista/v9/n1/pdf/v9n1a03.pdf>. Acesso em: 21 mar. 2009.

TAKUSHI, S.A.M. et al. Motivação de gestantes para o aleitamento materno. Rev. Nutr., v.21, n.5, p.491-502, 2008.

TOMA, T.S.; REA, M.F. Benefícios da amamentação para a saúde da mulher e da criança: um ensaio sobre as evidências. Cad. Saude Publica, v.24, supl.2, p.S235-46, 2008.

UNICEF. Fundo das Nações Unidas para a Infância. Iniciativa Hospital Amigo da Criança: revista, atualizada e ampliada para o cuidado integrado. Módulo 3 promovendo e incentivando a amamentação em um Hospital Amigo da Criança: curso de vinte horas para equipes de maternidade. Brasília: Ministério da Saúde; 2009. (Série A. Normas e Manuais Técnicos). Disponível em: <http://portal.saude.gov.br/portal/ arquivos/pdf/modulo3_ihac_alta.pdf >. Acesso em: 14 nov. 2009.

VIANNA R.P.T. et al. A prática de amamentar entre mulheres que exercem trabalho remunerado na Paraíba, Brasil: um estudo transversal. Cad. Saude Publica, v.23, n.10, p.2403-9, 2007.

VITOLO, M.R. et al. Depressão e suas implicações no aleitamento materno. Rev.

Psiquiatr. Rio Gd. Sul, v.29, n.1, p.28-34, 2007. 
FUJIMORI, E. et al. Aspectos relacionados con el establecimiento y al mantenimiento de la lactancia materna exclusiva desde la perspectiva de mujeres atendidas en una unidad básica de salud. Interface - Comunic., Saude, Educ., v.14, n.33, p.315-27, abr./jun. 2010.

Con la propuesta de conocer aspectos relacionados al perido de establecimiento y mantenimiento de la lactancia materna exclusiva (AME) bajo la perspectiva de mujeres se ha realizado un estudio cualitativo con 12 madres de lactantes menores de seis meses atendidas en una unidad básica de salud. Entrevistas semi-estructuradas, grabadas, transcritas y sometidas al análisis de contenido revelaron las categorías: traumas mamilares; libre demanda; "leche floja"; salud psicológica de la nutriz; experiencia anterior en amamantamiento; amamantamiento y los múltiples papeles de la mujer, influencia de personas próximas. El establecimiento del AME se asocia a experiencias y percepciones acerca de la suficiencia de la leche, generando preocupaciones e inseguridad. Personas próximas, en especial familiares, influencian en el estabelecimiento y mantenimiento del AME de la misma forma que la sobrecarga de trabajo de la mujer, dentro y fuera del hogar. Es fundamental que los profesionales de salud conozcan estos aspectos que dificultan o que facilitan el estabelecimiento y el mantenimiento de la lactancia materna para orientar acciones.

Palabras clave: Lactancia materna. Relaciones interpersonales. Apoyo social. Investigación cualitativa. 